\title{
Red Wine Polyphenols Prevent Cyclosporine-Induced Nephrotoxicity at the Level of the Intrinsic Apoptotic Pathway
}

\author{
R. REZZANi ${ }^{1}$, S. TENGATTINI ${ }^{1}$, F. BONOMINI ${ }^{1}$, F. FILIPPINI ${ }^{1}$, O. PECHÁŇOVÁ ${ }^{2}$, \\ R. BIANCHI ${ }^{1}$, R. ANDRIANTSITOHAINA ${ }^{3}$
}

${ }^{1}$ Division of Human Anatomy, Department of Biomedical Sciences and Biotechnology, University of Brescia, Brescia, Italy, ${ }^{2}$ Institute of Normal and Pathological Physiology, Centre of Excellence for Cardiovascular Research, Slovak Academy of Sciences, Bratislava, Slovak Republic, ${ }^{3}$ INSERM UMR 771, Angers; CNRS UMR 6214, Angers; Université d'Angers, UFR de Médecine, France

Received April 2, 2008

Accepted June 30, 2008

On-line July 25, 2008

\begin{abstract}
Summary
Flavonoids, polyphenol derivatives of plant origin, possess a broad range of pharmacological properties. A number of studies have found both pro/anti-apoptotic effects for many of these compounds. For these reasons we investigated whether Provinols ${ }^{\mathrm{T}}$, flavonoids obtained from red wine, have antiapoptotic properties. The investigations have been carried out in rats treated with Cyclosporine A (CSA). In particular, four groups of rats have been treated for 21 days with either olive oil (control group), with $\operatorname{CsA}$, with Provinols ${ }^{\mathrm{TM}}$, or with $\mathrm{CsA}$ and Provinols ${ }^{\mathrm{TM}}$ simultaneously. Oxidative stress, systolic blood pressure, body weight, biochemical parameters and different markers of pro/anti-apoptotic pathway were measured. CSA produced an increase of systolic blood pressure, a decrease in body weight, serum creatinine levels, urinary total protein concentration and creatinine clearance. Moreover, CsA induced renal alterations and the translocation of Bax and cytochrome c from cytoplasm to mitochondria and vice versa. These changes activated the caspase cascade pathway, that leads to morphological and biochemical features of apoptosis. Provinols ${ }^{\mathrm{TM}}$ restored morphological and biochemical alterations and prevented nephrotoxicity. In conclusion, this study may augment our current understanding of the controversial pro-/anti-apoptotic properties of flavonoids and their molecular mechanisms.
\end{abstract}

\section{Key words}

Apoptosis • Cyclosporine nephrotoxicity • Immunohistochemistry - Kidney disease $\bullet$ Provinols $^{\mathrm{TM}}$

\section{Corresponding author}

R. Rezzani, Department of Biomedical Sciences and Biotechnology, Division of Human Anatomy, University of Brescia,
Viale Europa 11, 25123, Brescia, Italy. Fax: +39 0303717486. E-mail: rezzani@med.unibs.it

\section{Introduction}

Plants have been used for the prevention and treatment of various human diseases throughout history. Some natural foods (vegetables, red wine, some other beverages and fruits) are considered to possess beneficial physiological effects such as antioxidant, anti-cancer, anti-aging, and anti-inflammatory effects. The polyphenols of plants in particular are major compounds with antioxidant effects (Yokozawa and Nakagawa 2004, Durak et al. 2007). In general, more than two thirds of the polyphenols consumed in the diet are flavonoids. Red wine flavonoids have generated considerable interest especially due to their in vivo and in vitro antioxidant capabilities. Their beneficial effects have been described mainly in relation to the French paradox phenomenon as well to the Mediterranean diet. In fact, the Mediterranean diet, rich in fruits and red wine, was shown to protect against the development of cardiovascular diseases and atherosclerosis (Carollo et al. 2007, Pechán̆ová et al. 2006). Another therapeutically relevant effect of flavonoids may be their ability to induce nitric oxide production and vasodilatation as well as the expression of genes that protect cardiovascular system (Curin and Andriantsitohaina 2005). Recently, the possible advantage of moderate wine consumption in patients with 
chronic renal failure was hypothesized (Caimi et al. 2004) and the protective role of flavonoids on nephrotoxicity, induced by an immunosuppressive drug, have been shown. In particular, it has been demonstrated that Provinols ${ }^{\mathrm{TM}}$, a flavonoid mixture isolated from red wine containing (in $\mathrm{mg} / \mathrm{g}$ of dry powder) 480 proanthocyans, 61 total anthocyanins, 19 free anthocyanins, 38 cathechin, 18 hydroxycinamic, 14 flavonols and 370 polymeric tannins (Pecháňová et al. 2006), was able to minimize renal side effects of cyclosporine A (CsA) treatment.

However, despite many studies that have been conducted on flavonoid functions, their antioxidant properties remain somewhat debatable, and the detailed molecular mechanisms of their effects remain largely unknown as well as their pro-/anti-apoptotic effects.

The objective of the present study was to assess the apoptosis-modulating effects of Provinols ${ }^{\mathrm{TM}}$ and to elucidate the molecular mechanisms underlying its activity on the apoptosis of renal parenchyma. The study has been carried out using an experimental model including the treatment with cyclosporine $\mathrm{A}$, the most used immunosuppressive drug. This drug is normally used after solid-organ transplantation and in the treatment of several autoimmune diseases (Kahan 1989, de Mattos et al. 1996), but several renal and vascular toxic effects have been found to be associated with life-long treatment of transplanted patients with CsA and in experimental conditions (Burdmann et al. 2003, Rezzani 2004). The damage is related to tubulointerstitial fibrosis, mainly in proximal tubules and glomerular vasoconstriction (Justo et al. 2003, Rezzani et al. 2005). Moreover, several groups have identified an increased rate of tubular cell apoptosis both in vitro and in vivo indicating apoptosis as a mechanism of CsA nephrotoxicity (Hortelano et al. 2000, Ortiz et al. 1998, Yang et al. 2002). It has been shown that apoptosis induced by CsA is associated with the translocation of Bax to the mitochondria and that Bax antisense oligodeoxynucleotides is protected from CsAinduced apoptosis. CsA promoted a caspase-independent release of cytochrome $\mathrm{c}$ and Smac/Diablo from mitochondria and also led to a caspase-dependent loss of mitochondrial membrane potential. Caspase-2, caspase- 3 and caspase-9 were activated and specific caspase inhibitor prevented apoptosis (Justo et al. 2003).

Here we studied renal cytoarchitecture and physiological functions as well as some markers of oxidative stress (Chi et al. 2005) and apoptotic pathway, such as superoxide dismutase (SOD), Bax, caspase- 3 and cytochrome $\mathrm{c}$ in animals treated with cyclosporine A and flavonoids.

Our findings indicate that apoptosis is regulated by Provinols ${ }^{\mathrm{TM}}$ underlying its role in the correction of CsA-induced both structural and functional changes of the kidney. Moreover, our data also add new insights into the controversies regarding the anti-/pro-apoptotic properties of dietary flavonoids.

\section{Materials and Methods}

\section{Drugs and chemicals}

Cyclosporine A (Sandimmun infusion concentrate $100 \mathrm{mg} / \mathrm{ml}$ ) was obtained from Novartis (East Hanover, NJ, USA) and dissolved in olive oil to a final concentration of $50 \mathrm{mg} / \mathrm{ml}$. Provinols ${ }^{\mathrm{TM}}$ (dry powder) has been supplied from the Société Francaise de Distilleries (Vallont Pont d'Arc, France).

\section{Animals}

Male Wistar rats $(220 \pm 6 \mathrm{~g})$ were used (Harlan, Italy). All animals were fed with standard rat chow and water ad libitum and kept in a temperature-controlled environment $\left(20-22{ }^{\circ} \mathrm{C}\right)$ with an alternating $12 \mathrm{~h}$ lightdark cycle. The experimental protocol was approved and conducted in accordance with the Italian Ministry of Health and complied with the Guiding Principles in the Use of Animals in Toxicology.

\section{Experimental protocol}

Experiments were performed on four groups consisting of twenty rats each. The control group was treated with the CsA vehicle, olive oil ( $1 \mathrm{ml} / \mathrm{kg}$, s.c.) for 21 days. The second group received $\mathrm{CsA}$ at a dose of $15 \mathrm{mg} / \mathrm{kg} /$ day, s.c., for 21 days. In the third group, rats were supplemented with Provinols ${ }^{\mathrm{TM}}(40 \mathrm{mg} / \mathrm{kg} / \mathrm{day}$ in the drinking water). To ensure that each rat received the complete dose of Provinols ${ }^{\mathrm{TM}}$, the calculated amount of Provinols ${ }^{\mathrm{TM}}$ was given to each animal in the appropriate volume of water $(0.2 \mathrm{mg} / \mathrm{ml})$. Daily water consumption was controlled, with graduated Richter tubes, and Provinols $^{\mathrm{TM}}$ concentration in the drinking fluid was adjusted, if necessary. The fourth group received Provinols $^{\mathrm{TM}}$ concurrently during CsA injections for 21 days.

\section{Measurements of body weight, systolic blood pressure}

Body weight and systolic blood pressure (SBP) were measured weekly. SBP (initial value $97 \pm 3 \mathrm{~mm} \mathrm{Hg}$ ) 
was measured with a tail-cuff technique (Apollo-2AB Blood Pressure Analyzer, Woodland Hills, CA, USA). Values for SBP were obtained by averaging readings from three measurements.

\section{Collection of samples}

At the end of the study, rats were housed individually in metabolic cages for a $24 \mathrm{~h}$ urine collection. Urine volumes were measured and urine samples were stored at $-20{ }^{\circ} \mathrm{C}$ until the determination of biochemical parameters. After animal decapitation under anesthesia, blood samples were obtained. One part was used to determine the concentration of drug in whole blood using a TDx/TDxFLx cyclosporine assay kit from Abbott Laboratories; the other part was centrifuged at $1800 \mathrm{~g}$ for $15 \mathrm{~min}$ at $4{ }^{\circ} \mathrm{C}$ and sera were separated and stored at $-20{ }^{\circ} \mathrm{C}$ until assayed for creatinine. Kidneys were excised quickly, washed immediately with ice-cold physiological saline, blotted dry and weighed. Portions were taken for histopathological study and the remaining parts of the kidneys were homogenized in ice-cold saline, and were centrifuged at $3000 \mathrm{~g}$ for $10 \mathrm{~min}$ at $4{ }^{\circ} \mathrm{C}$. The supernatants were divided into aliquots and kept at $-20{ }^{\circ} \mathrm{C}$ until assayed for glutathione (GSH).

\section{Measurements of kidney function}

Serum creatinine was analyzed using a commercial kit from Sigma-Aldrich Diagnostics (St. Louis, MO, USA) and the urinary protein concentration was determined using a kit from Biomerieux (Marcy-l'Etoile, France). Glomerular filtration rate was calculated as creatinine clearance using standard formulae according to Shi et al. (2004).

Serum creatinine results are expressed as $\mathrm{mg} / \mathrm{dl}$, those of urinary protein concentration as $\mathrm{g} / \mathrm{dl}$ and those of creatinine clearance as $\mathrm{ml} / \mathrm{min} / \mathrm{kg}$, each of them being based upon at least 6 independent determinations.

\section{Determination of renal GSH content}

Renal GSH was determined as described previously by Dudek et al. (2005), using a colorimetric assay Bioxytech GSH-400 (Oxis Research, Foster City, CA, USA) according to the manufacturer's instructions. The absorbance was measured at $400 \mathrm{~nm}$ and the GSH concentration was calculated using a standard solution of GSH. Results are expressed as $\mu \mathrm{mol} / 1$.

\section{Histopathological studies}

The kidney portions taken for histopathological studies were divided in two parts. One part was fixed in 10 $\%$ formalin, embedded in paraffin according to standard procedures and sectioned at $5 \mu \mathrm{m}$ by a microtome. These sections were deparaffinized, rehydrated and finally treated with hematoxylin-eosin and DNA fragmentation (TUNEL staining) for morphological studies and with caspase-3, SOD and Bax for immunohistochemical studies. The second part of each sample was frozen and used for histochemical study (cytochrome c).

\section{DNA Fragmentation (TUNEL staining)}

Kidney sections were labeled using TdT-Fragel DNA Fragmentation Detection Kit (TUNEL staining) according to manufacturer's instructions (Calbiochem, San Diego, CA). The number of TUNEL-positive cells was quantified by taking the average of 20 fields at x 200 magnification.

Immunohistochemical localization of SOD, caspase-3 and Bax proteins

Before the immunohistochemical analysis, sections were deparaffinized, rehydrated, and then immersed in $3 \%$ hydrogen peroxide $\left(\mathrm{H}_{2} \mathrm{O}_{2}\right)$ in methanol for $30 \mathrm{~min}$ to block endogenous peroxidase activity. Sections were incubated for $60 \mathrm{~min}$ at room temperature in normal goat serum for SOD, caspase-3 and Bax (1:5; Dakopatts, Milan, Italy) and serially treated with respective rabbit polyclonal antibodies: anti-SOD (diluted 1:500; QED Bioscience Inc, San Diego, CA, USA), anticaspase-3 (1:50; Cell Signaling Technology, Danvers, MA) and anti-Bax (1:100; Santa Cruz Biotechnology, Santa Cruz, CA, USA) at $4{ }^{\circ} \mathrm{C}$ overnight. Thereafter, sections were washed in TBS $0.1 \mathrm{M}, \mathrm{pH} 7.4$, and then incubated with a biotinylated secondary antibody (goat anti-rabbit, 1:50; Dakopatts, Milan, Italy) for $60 \mathrm{~min}$ and then with the avidin-biotin horseradish peroxidase complex (ABC kit; Dakopatts, Milan, Italy) for additional $60 \mathrm{~min}$. Sections were then immersed in a solution of $0.05 \%$ 3,3-diamino-benzidine tetrahydrochloride (DAB, Sigma-Aldrich, Milan, Italy) and $0.03 \% \mathrm{H}_{2} \mathrm{O}_{2}$. Finally, sections were counterstained with hematoxylin, dehydrated, and mounted.

\section{Cytochrome c histochemistry}

Briefly, frozen samples were cut in a cryostat to a thickness of $5 \mu \mathrm{m}$. The sections were incubated for $1 \mathrm{~h}$

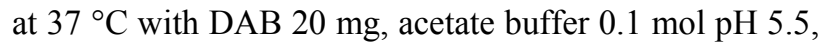
$\mathrm{MnCl}_{2} \quad 0.1 \%$ and $0.1 \mathrm{ml} \mathrm{H}_{2} \mathrm{O}_{2}$ and then dehydrated, counterstained with hematoxylin and mounted according 
Table 1. Effects of Provinols ${ }^{\mathrm{TM}}$ on body weight, blood pressure, kidney function, CSA blood level and GSH activities in CSA-treated rats.

\begin{tabular}{|c|c|c|c|c|}
\hline & CsA & Control & Provinols $^{\mathrm{TM}}$ & CsA+Provinols ${ }^{\mathrm{TM}}$ \\
\hline Body weight (g) & $242 \pm 15^{*}$ & $312 \pm 12$ & $315 \pm 9$ & $298 \pm 12$ \\
\hline Systolic BP (mm Hg) & $145 \pm 3^{*}$ & $98 \pm 4$ & $96 \pm 5$ & $97 \pm 3$ \\
\hline Serum creatinine (mg/dl) & $1.38 \pm 0.32 *$ & $0.53 \pm 0.27$ & $0.65 \pm 0.37$ & $0.63 \pm 0.33$ \\
\hline Urinary protein $(g / d l)$ & $750 \pm 23 *$ & $357 \pm 12$ & $389 \pm 15$ & $372 \pm 20$ \\
\hline $\operatorname{Ccr}(\mathrm{ml} / \mathrm{min} / \mathrm{kg})$ & $1.4 \pm 0.07 *$ & $3.1 \pm 0.91$ & $2.9 \pm 0.12$ & $3.0 \pm 0.19$ \\
\hline CsA blood level $(\mu \mathrm{mol} / \mathrm{l})$ & $6.57 \pm 1.42$ & 0 & 0 & $6.35 \pm 0.96$ \\
\hline GSH (mmol/l) & $0.31 \pm 0.06^{*}$ & $2.47 \pm 0.09$ & $2.34 \pm 0,08$ & $1.3 \pm 0.05$ \\
\hline
\end{tabular}

$* \mathrm{p}<0.05$ vs control.

For quantitative analysis, the 5 - $\mu$ m-thick sections including cortical and medullary region were evaluated at x100 magnification using an optical microscope (BX50; Olympus, Hamburg, Germany) equipped with an image analyzer (Image pro Plus; Milan, Italy). The integrated optical density (IOD) was calculated for arbitrary areas, measuring 10 fields with the same area for each sample. Data were pooled to represent a mean value, and a statistical analysis was applied to compare the results obtained from the different experimental groups.

\section{Statistical analysis}

Samples were analyzed and scored blindly. Values are expressed as the mean \pm S.D. Data were analyzed using the ANOVA and Bonferroni test. $P<0.05$ was considered significant.

\section{Results}

Effect of Provinols ${ }^{T M}$ on body weight and blood pressure in CsA-treated rats

CsA treatment significantly reduced body weight as compared to control rats. Provinols ${ }^{\mathrm{TM}}$ alone did not affect body weight but completely prevented its decrease upon CsA treatment (Table 1). SBP was significantly increased at the end of CsA treatment from $98 \pm 4 \mathrm{~mm} \mathrm{Hg}$ in control rats to $145 \pm 3 \mathrm{~mm} \mathrm{Hg}$ in CsA-treated rats. Provinols $^{\mathrm{TM}}$ completely prevented the rise in SBP induced by CsA treatment (Table 1).

\section{Effect of Provinols ${ }^{T M}$ on renal functions}

CsA-induced nephrotoxicity was reflected by the significant increase in serum creatinine level and urinary total protein concentration, and by a decrease in creatinine clearance (Table 1). Provinols ${ }^{\mathrm{TM}}$ alone did not significantly affect these parameters but it restored these values toward those of controls when it was administered with CsA. Thus, Provinols ${ }^{\mathrm{TM}}$ restored CsA-induced renal dysfunction. CsA blood levels were not affected by Provinols $^{\mathrm{TM}}$ (Table 1).

\section{Effect of Provinols ${ }^{T M}$ on CSA-induced oxidative stress}

Glutathione (GSH), an antioxidant enzyme, was significantly reduced after CsA treatment when compared to that of control rats. Provinols ${ }^{\mathrm{TM}}$ inhibited the CsAinduced depletion of GSH. Thus GSH concentration was not significantly different between control and Provinols $^{\mathrm{TM}}$ plus CsA group (Table 1).

\section{Histopathological studies - hematoxylin-eosin}

Renal CsA damage was mainly observed in the cortical region and consisted of tubular and glomerular injury with dilation of the lumen and Bowman's capsule, respectively (Fig. 1A). On the contrary, kidneys from control, Provinols ${ }^{\mathrm{TM}}$ and CsA plus Provinols ${ }^{\mathrm{TM}}$-treated rats showed normal cytoarchitecture (Figs 1B, 1C and 1D).

\section{DNA fragmentation (TUNEL staining)}

The number of TUNEL-positive cells was high in CsA-treated rats (Fig. 2A) compared to those from control and Provinols ${ }^{\mathrm{TM}}$-treated animals (Figs $2 \mathrm{~B}$ and 2C). Following 21 days of CsA plus Provinols ${ }^{\mathrm{TM}}$ treatment, TUNEL-positive cells were significantly reduced (Fig. 12D) compared to CsA group and it was similar to the control group (quantitative data - Fig. 2E).

Immunohistochemical studies for SOD, caspase-3 and Bax

CsA treatment significantly decreased SOD expression (Fig. 3A) in cortical renal parenchyma 


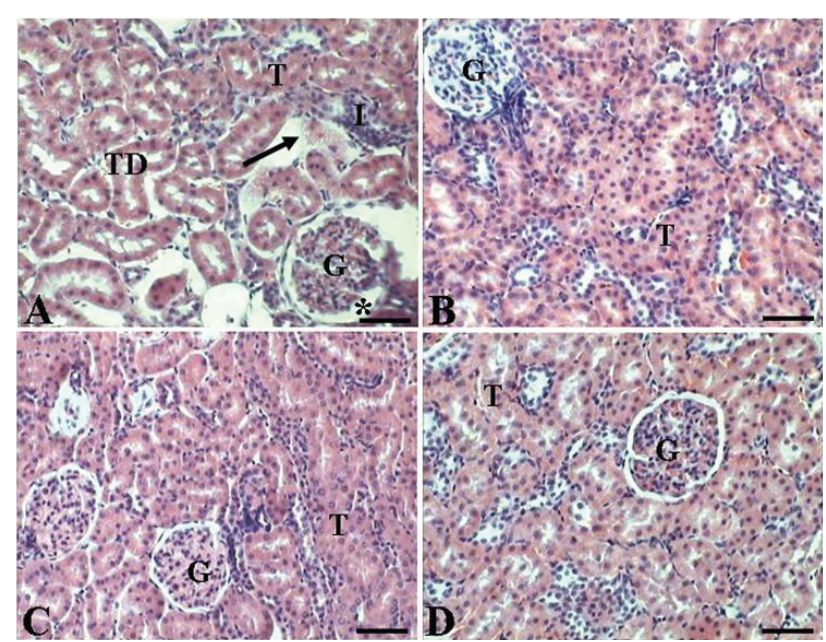

Fig. 1. Hematoxylin-eosin staining of renal cortex in rat: (A) CsA, (B) control, (C) Provinols ${ }^{\mathrm{TM}}$, (D) CSA + Provinols $^{\mathrm{TM}}$ (Bar: $\left.50 \mu \mathrm{m}\right)$. $\mathrm{T}=$ tubules; $\mathrm{G}=$ glomeruli; $\mathrm{TD}=$ tubular dilation; $\mathrm{I}=$ infiltrates. The arrow shows renal fibrosis; the asterisk shows Bowman's capsule dilation.

compared to control and Provinols ${ }^{\mathrm{TM}}$-treated rats (Figs $3 \mathrm{~B}$ and $3 \mathrm{C}$ ). CsA plus Provinols ${ }^{\mathrm{TM}}$ increased SOD expression toward that of control rats (Fig. 3D).

Figure $3 \mathrm{G}$ shows that CsA administration induced a huge caspase- 3 expression when compared to the weak expression observed in control, Provinols ${ }^{\mathrm{TM}}$ and CsA plus Provinols ${ }^{\mathrm{TM}}$-treated rats (Figs $3 \mathrm{H}, 3 \mathrm{I}$ and $3 \mathrm{~L}$ ). All data were confirmed also by quantitative analysis (Figs 3F and 3N).

Furthermore, Bax immunostaining, after CsA treatment, showed a granular positivity in tubular renal structures (Fig. 4A), whereas a high and diffuse positive staining was observed in renal tubules of control, Provinols $^{\mathrm{TM}}$ and CsA plus Provinols ${ }^{\mathrm{TM}}$-treated rats (Figs 4B, 4C and 4D).

\section{Cytochrome c histochemistry}

We observed a diffuse positivity after CsA treatment (Fig. 4F) in renal tubules and a "dot reaction product" in control, Provinols ${ }^{\mathrm{TM}}$ and CsA plus Provinols $^{\mathrm{TM}}$-treated animals (Figs $4 \mathrm{G}, 4 \mathrm{H}$ and $4 \mathrm{I}$ ). This cytoplasmic positivity was evident in the epithelial cells of tubular structures.

\section{Discussion}

The flavonoids are a group of natural products currently receiving a great deal of attention. Several studies have reported that some flavonoids, including for instance kaempferol and quercetin, exert anti-oxidant effects and can also inhibit carcinogenesis (Cody 1988,

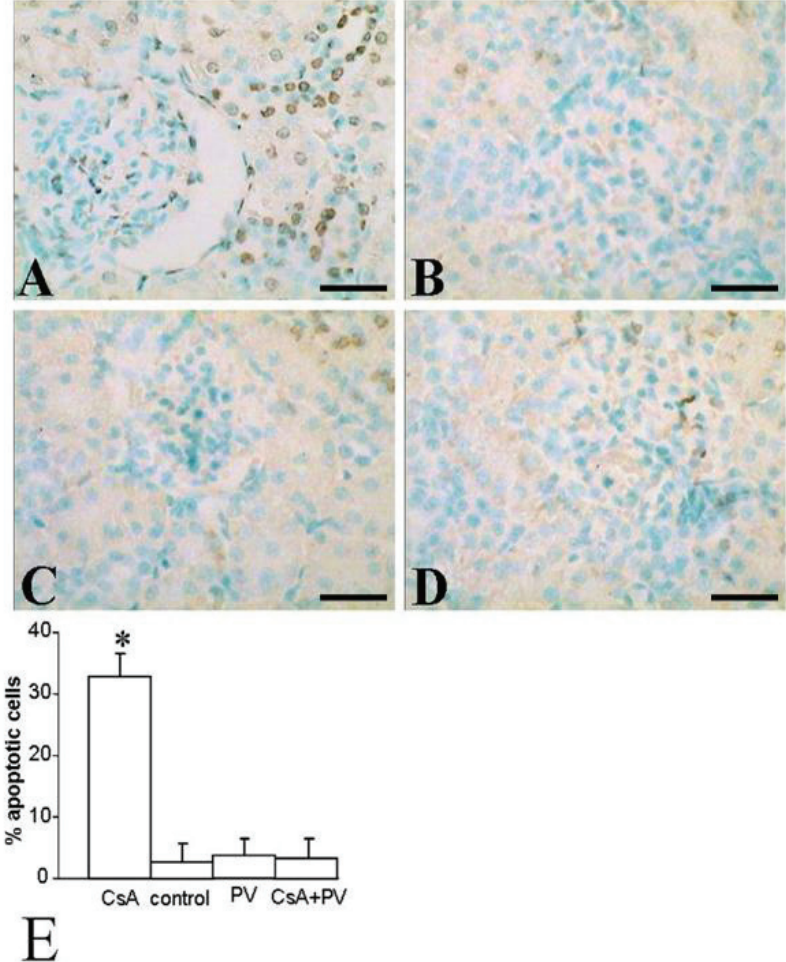

Fig. 2. TUNEL staining in renal cortex of rat: (A) CSA, (B) control, (C) Provinols ${ }^{\mathrm{TM}}$, (D) CSA + Provinols ${ }^{\mathrm{TM}}$ (Bar: $\left.30 \mu \mathrm{m}\right)$. (E) shows quantitative analysis (IOD) of apoptotic cells. *Statistical significant $(P<0.05)$ when compared with control.

Lee et al. 2005). Besides these antitumor activities, some flavonoids have been observed to exhibit a variety of beneficial biological activities, including antihypertensive, antiviral, and anti-inflammatory properties. Some flavonoids have also been reported to harbor antiapoptotic properties (Shi et al. 2003). Despite the many studies conducted to determine the variety of biological functions associated with the flavonoids, the precise molecular mechanisms underlying their cellular effects remain largely unknown.

To the best of our knowledge, no previous studies have focused on the anti-apoptotic effects of Provinols ${ }^{\mathrm{TM}}$, flavonoids from red wine. Here we found that Provinols ${ }^{\mathrm{TM}}$ : i) prevented the increase of SBP induced by CsA-treatment, and ii) improved renal function and prevented CsA-induced nephrotoxicity through an interaction with the apoptotic pathway.

\section{Provinols ${ }^{T M}$ and blood pressure}

The mechanisms by which Provinols ${ }^{\mathrm{TM}}$ prevented blood pressure increase have not been assessed here, but many authors reported the antihypertensive effect of Provinols ${ }^{\mathrm{TM}}$ in different experimental models of hypertension. Administration of Provinols ${ }^{\mathrm{TM}}$ reduced the 

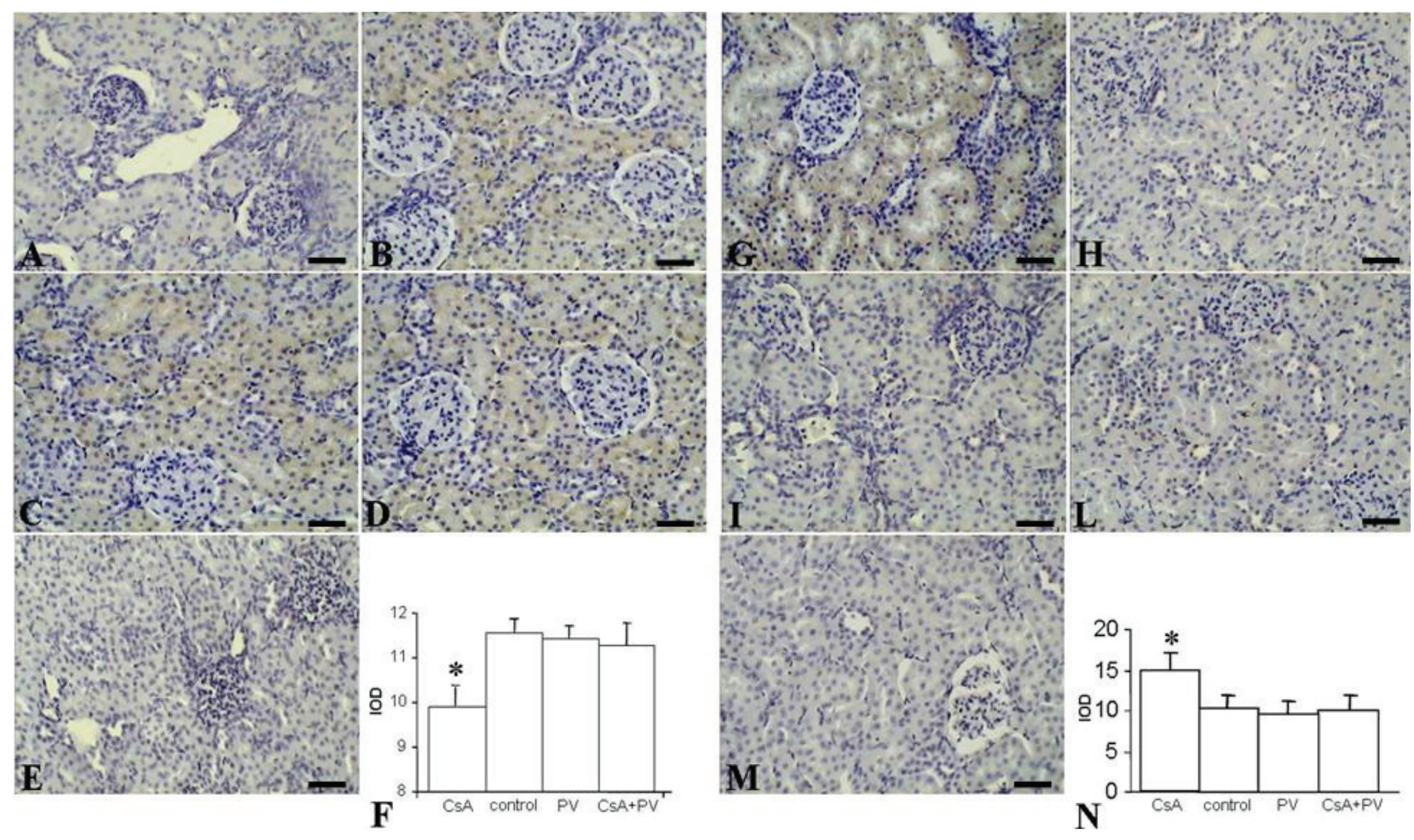

Fig. 3. Effect of Provinols ${ }^{T M}$ on SOD (A-E) and caspase-3 (G-M) expression in CsA (A, G), control (B, H), Provinols ${ }^{T M}(C, I)$, CSA + Provinols $^{\mathrm{TM}}(\mathrm{D}, \mathrm{L})$-treated rats and in negative control $(\mathrm{E}, \mathrm{M})($ Bar: $40 \mu \mathrm{m}) .(\mathrm{F}, \mathrm{N})$ show quantitative analysis (IOD) of SOD and caspase3 expression. * Statistically significant $(P<0.05)$ when compared with controls.
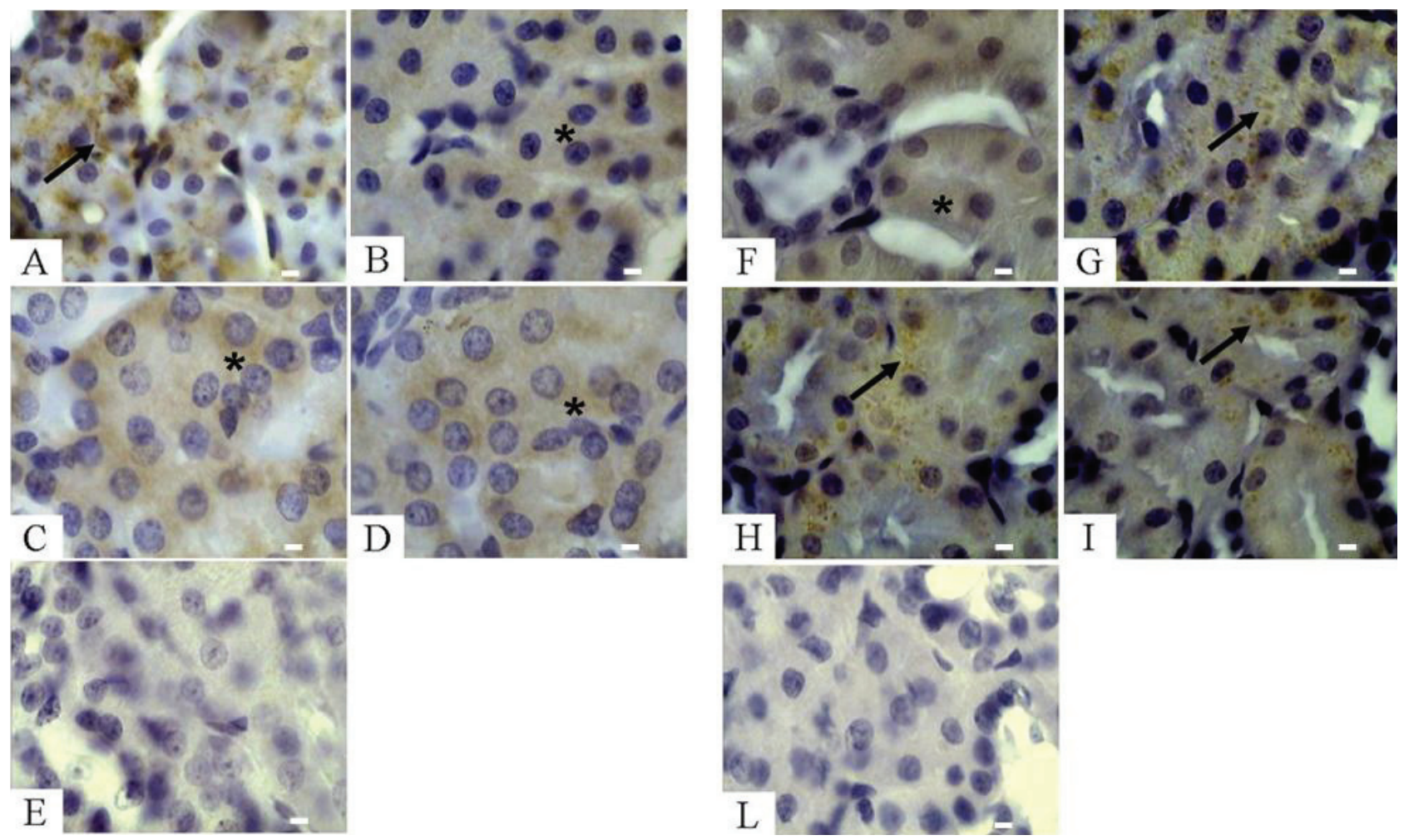

Fig. 4. Effect of Provinols ${ }^{T M}$ on $B a x(A-E)$ and cytochrome $c(F-L)$ staining respectively in $\operatorname{Cs} A(A, F)$, control $(B, G)$, Provinols ${ }^{T M}(C, H)$, $\mathrm{CSA}+$ Provinols $^{\mathrm{TM}}(\mathrm{D}, \mathrm{I})$-treated rats and in negative control $(\mathrm{E}, \mathrm{L})($ Bar: $4 \mu \mathrm{m})$. The arrows show the granular positivity; the asterisks show the diffuse positivity. 
increase in both blood pressure and protein synthesis in the heart and aorta caused by chronic inhibition of NO synthesis (Bernátová et al. 2002, Pecháňová et al. 2004). This was accompanied by reduced end-organ damage such as myocardial fibrosis and aortic thickening. Provinols $^{\mathrm{TM}}$ also prevented endothelial dysfunction that was associated with an increase of NO-synthase activity, a moderate enhancement of endothelial NO synthase expression and a reduction of oxidative stress in the left ventricle and aorta. Moreover, angiotensin II-induced hypertension, associated with endothelial dysfunction and an excessive NADPH oxidase-dependent vascular formation of reactive oxygen species (ROS), is prevented by administration of other red wine polyphenols (Sarr et al. 2006). Thus, the beneficial effects of Provinols ${ }^{\mathrm{TM}}$ in prevention of hypertension may result from their complex influence on the NO and ROS balance in the cardiovascular system. Therefore, the antihypertensive Provinols $^{\mathrm{TM}}$ effect probably accounts at least partially for the reduced end-organ damage induced by CsA treatment in terms of nephrotoxicity. The latter properties of Provinols ${ }^{\mathrm{TM}}$ may protect the kidney against CsA-induced alterations in renal blood flow and kidney architecture, including tubular injury and interstitial fibrosis, especially at the level of the cortex, and therefore prevent the decrease of creatinine clearance.

\section{Provinols ${ }^{T M}$ and renal function}

In this study we demonstrated that Provinols ${ }^{\mathrm{TM}}$ exerts its protective effects also through an interaction with the apoptosis pathway. In fact, evidence was provided that Provinols ${ }^{\mathrm{TM}}$ prevented Bax and cytochrome c translocation from cytoplasm to mitochondria and vice versa respectively. Once released, cytochrome c triggers the activation of caspase cascade activating the initiator capsases, such as caspase-3 induction. Finally, caspase-3, in turn cleaves various proteins leading to morphological and biochemical features characteristic for apoptosis (Gupta and Knowlton 2005, Orrenius 2004). Interestingly, Provinols ${ }^{\mathrm{TM}}$ treatment decreased caspase 3 activation and apoptosis. Our data showing that CsAinduced nephrotoxicity was linked to apoptosis, are in agreement with those reported in cultured renal tubular cells subjected to $3 \mathrm{~h}$ of ATP depletion with azide. Brooks et al. (2005) found that ATP depletion was mediated by a pathway involving Bax translocation, cytochrome c release, and caspase cascade activation. Moreover, they demonstrated that physiological Bax immunoreactivity appeared as fine diffuse labeling in the cytoplasm and that, during apoptosis, its expression was observed as a granular labeling linked to the mitochondria. Furthermore, they suggested that granular cytochrome c immunopositivity, consistent with its expected mitochondrial localization in normal conditions, was detected as diffuse cytoplasmic positivity during apoptosis. Once released, cytochrome c activates the caspase cascade including caspase 3 and therefore apoptosis. In line with the present study we have shown that, delphinidin, an anthocyanin present in Provinols ${ }^{\mathrm{TM}}$ exerts an anti-apoptotic effect in endothelial cells through the NO guanylyl cyclase pathway, probably by upregulating endothelial NO synthase expression via the MEK1/2 pathway (Martin et al. 2003). Its preventive effect against cell death is associated with a strict control of calcium homeostasis and the inhibition of the release of cytochrome $\mathrm{c}$ from the mitochondria. Altogether, the anti-apoptotic effect of Provinols ${ }^{\mathrm{TM}}$, at least through endothelial protection, may contribute to the beneficial effects of natural dietary polyphenolic compounds, including those contained in red wine, against CsAinduced nephrotoxicity. Our data are in agreement with those reported by Orrenius et al. (2004) with regard to morphological alterations and an increase in apoptotic cell number. These effects are partially linked both to its antioxidant and anti-inflammatory properties. Indeed, Provinols $^{\mathrm{TM}}$ enhanced the expression of the antioxidant enzymes (SOD and GSH) that, in turn, reduced ROS and oxidative stress. It is also possible that reduced ROS and oxidative stress reversed the intrinsic apoptotic pathway associated with mitochondria destabilization (Riles et al. 2006) following renal injury due to CsA-treatment.

In conclusion, this study may provide helpful information, allowing us to further address the controversial pro-/anti-apoptotic properties of various flavonoids. Our results also augment our current understanding of the molecular mechanisms underlying the differential cellular functions affected by flavonoid treatment.

\section{Conflict of Interest}

There is no conflict of interest.

\section{Acknowledgements}

The authors thank Ms Stefania Castrezzati for excellent technical assistance. This work was supported by a MURST grant $(60 \%, 2005)$ and APVV-0586-06 (O.P.). 


\section{References}

BERNÁTOVÁ I, PECHÁŇOVÁ O, BABÁL P, KYSELA S, ŠTVRTINA S, ANDRIANTSITOHAINA R: Wine polyphenols improve cardiovascular remodeling and vascular function in NO-deficient hypertension. Am $J$ Physiol 282: H942-H948, 2002.

BROOKS C, KETSAWATSOMKRON P, SUI Y, WANG J, WANG CY, YU FS, DONG Z: Acidic pH inhibits ATP depletion-induced tubular cell apoptosis by blocking caspase-9 activation in apoptosome. Am J Physiol Renal Physiol 289: F410-F419, 2005.

BURDMANN EA, ANDOH TF, YU L, BENNETT WM: Cyclosporine nephrotoxicity. Semin Nephrol 23: 465-476, 2003.

BURSTONE MS: New histochemical techniques for the demonstration of tissue oxidase (cytochrome oxidase). J Histochem Cytochem 7: 112-122, 1959.

CAIMI G, CAROLLO C, LO PRESTI R: Chronic renal failure: oxidative stress, endothelial dysfunction and wine. Clin Nephrol 62: 331-335, 2004.

CAROLLO C, PRESTI RL, CAIMI G: Wine, diet, and arterial hypertension. Angiology 58: 92-96, 2007.

CHI C, TANAKA R, OKUDA Y, IKOTA N, YAMAMOTO H, URANO S, OZAWA T, ANZAI K: Quantitative measurements of oxidative stress in mouse skin induced by X-ray irradiation. Chem Pharm Bull 53: 1411$1415,2005$.

CODY V: Crystal and molecular structures of flavonoids. Prog Clin Biol Res 280: 29-44, 1988.

CURIN Y, ANDRIANTSITOHAINA R: Polyphenols as potential therapeutical agents against cardiovascular diseases. Pharmacol Rep 57: 97-107, 2005.

De MATTOS AM, OLYAEI AJ, BENNETT WM: Pharmacology of immunosuppressive medications used in renal diseases and transplantation. Am J Kidney Dis 28: 631-667, 1996.

DUDEK H, FARBISZEWSKI R, RYDZEWSKA M, MICHNO T, KOZLOWSKI A: Concentration of glutathione (GSH), ascorbic acid (vitamin C) and substances reacting with thiobarbituric acid (TBA-rs) in single human brain metastases. Wiad Lek 58: 379-381, 2005.

DURAK I, CETIN R, CANDIR O, DEVRIM E, KILICOGLU B, AVCI A: Black grape and garlic extracts protect against cyclosporine A nephrotoxicity. Immunol Invest 36: 105-114, 2007.

GUPTA S, KNOWLTON AA: HSP60, bax, apoptosis and the heart. J Cell Mol Med 9: 51-58, 2005.

HORTELANO S, CASTILLA M, TORRES AM, TEJEDOR A, BOSCA L: Potentiation by nitric oxide of cyclosporin A and FK506-induced apoptosis in renal proximal tubule cells. J Am Soc Nephrol 11: 2315-2323, 2000.

JUSTO P, LORZ C, SANZ A, EGIDO J, ORTIZ A: Intracellular mechanisms of cyclosporin A-induced tubular cell apoptosis. J Am Soc Nephrol 14: 3072-3080, 2003.

KAHAN BD: Cyclosporine. $N$ Engl J Med 321: 1725-1738, 1989.

LEE ER, KANG YJ, KIM JH, LEE HT, CHO SG: Modulation of apoptosis in HaCaT keratinocytes via differential regulation of ERK signaling pathway by flavonoids. J Biol Chem 280: 31498-31507, 2005.

MARTIN S, GIANNONE G, ANDRIANTSITOHAINA R, MARTINEZ MC: Delphinidin, an active compound of red wine, inhibits endothelial cell apoptosis via nitric oxide pathway and regulation of calcium homeostasis. $\mathrm{Br} J$ Pharmacol 139: 1095-1102, 2003.

ORRENIUS S: Mitochondrial regulation of apoptotic cell death. Toxicol Lett 149: 19-23, 2004.

ORTIZ A, LORZ C, CATALAN M, ORTIZ A, COCA S, EGIDO J: Cyclosporine A induces apoptosis in murine tubular epithelial cells: role of caspases. Kidney Int Suppl 68: S25-S29, 1998.

PECHÁŇOVÁ O, BERNÁTOVÁ I, BABÁL P, MARTINEZ MC, KYSELÁ S, ŠTVRTINA S, ANDRIANTSITOHAINA R: Red wine polyphenols prevent cardiovascular alterations in L-NAME-induced hypertension. J Hypertens 22: 1551-1559, 2004.

PECHÁŇOVÁ O, REZZANI R, BABÁL P, BERNÁTOVÁ I, ANDRIANTSITOHAINA R: Beneficial effects of Provinols: cardiovascular system and kidney. Physiol Res 55 (Suppl 1): S17-S30, 2006.

REZZANI R: Cyclosporine A and adverse effects on organs: histochemical studies. Prog Histochem Cytochem 39: 85128, 2004. 
REZZANI R, RODELLA L, BIANCHI R, GOODMAN AI, LIANOS EA: Protective effects of heme-oxygenase expression in cyclosporine A-induced injury. Curr Neurovasc Res 2: 157-161, 2005.

RILES WL, ERICKSON J, NAYYAR S, ATTEN MJ, ATTAR BM, HOLIAN O: Resveratrol engages selective apoptotic signals in gastric adenocarcinoma cells. World J Gastroenterol 12: 5628-5634, 2006.

SARR M, CHATAIGNEAU M, MARTINS S, SCHOTT C, EL BEDOUI J, OAK MH, MULLER B, CHATAIGNEAU T, SCHINI-KERTH VB: Red wine polyphenols prevent angiotensin II-induced hypertension and endothelial dysfunction in rats: role of NADPH oxidase. Cardiovasc Res 71: 794-802, 2006.

SHI S, ZHENG S, ZHU Y, JIA C, XIE H: Inhibitory effect of tea polyphenols on renal cell apoptosis in rat test subjects suffering from cyclosporine-induced chronic nephrotoxicity. Chin Med J 116: 1345-1350, 2003.

SHI SH, ZHENG SS, JIA CK, ZHU YF, XIE HY: Inhibitory effect of tea polyphenols on transforming growth factorbeta1 expression in rat with cyclosporine A-induced chronic nephrotoxicity. Acta Pharmacol Sin 25: 98-103, 2004.

YANG CW, FAULKNER GR, WAHBA IM, CHRISTIANSON TA, BAGBY GC, JIN DC, ABBOUD HE, ANDOH TF, BENNETT WM: Expression of apoptosis-related genes in chronic cyclosporine nephrotoxicity in mice. Am J Transplant 2: 391-399, 2002.

YOKOZAWA T, NAKAGAWA T: Inhibitory effects of Luobuma tea and its components against glucose-mediated protein damage. Food Chem Toxicol 42: 975-981, 2004. 